\title{
La biopolítica: una nueva técnica de control en Chile
}

\author{
Biopolitics: A new control technique in Chile
}

Elizabeth Maldonado Solar?

\begin{abstract}
"La rebeldía individual, para trascender el disgusto personal necesita devenir en rebeldía social, ir más allá de la propia percepción de la discriminación. Es preciso reconocerla en todos los semejantes, reconocerla en las otras e identifi-

carnos con las otras" Julieta Kirkwood ${ }^{2}$
\end{abstract}

\begin{abstract}
Resumen
El desarrollo de la economía moderna bajo la forma del capitalismo ha constituido un sistema universal de asignaciones de derechos, libertades y garantías, pero, a su vez, ha desplegado las nuevas tecnologías para economizar el poder y organizar a la ciudadanía en términos de población.

Desde una "tecnología política del cuerpo", es posible observar un vínculo entre las relaciones de poder que se ponen en práctica una vez que comienza una nueva forma de gobernar una sociedad.

El presente artículo propone analizar el momento político desde donde surge una nueva razón del arte de gobernar y así visualizar de qué modo surge la biopolítica en el Estado chileno como forma disciplinaria para el control ciudadano y cómo este atañe, afecta y controla el cuerpo de la mujer.
\end{abstract}

Palabras clave: mercado - poder - cuerpo - mujer - biopolítica.

\begin{abstract}
The development of the modern economy in the shape of capitalism has been a universal system of allocation of rights, liberties and guarantees, but, in turn, has spread new technologies to save power and organize citizens in terms of population.

From a "political technology of the body", you can see a link between the power relations that are implemented once it starts a new way of governing a society.

This article aims to analyze the political moment where emerges a new reason of governing and thus visualize how Biopolitics arises in the Chilean state as a disciplinary way to the citizen control and as this regards, affects and controls the body of the woman.
\end{abstract}

Key words: market - power - body - woman - Biopolitics.

Fecha de recepción: 1 de junio de 2013

Fecha de aprobación: 2 de octubre de 2014

Profesora de Filosofía (Universidad de Valparaíso, Chile), Magíster en Filosofía Política (Universidad de Santiago de Chile).

2 Julieta Kirkwood, Ser Política en Chile, Ed. Cuarto Propio,1990.

PUNTO GÉNERO / 23 
Para establecer la conexión de la biopolítica con el Estado chileno es menester comprender en qué escenario histórico político comienza a desplegarse esta técnica como nuevo control ciudadano.

La construcción del cuerpo policial, como primera forma de control disciplinario y razón de Estado, es el comienzo de lo que se denomina sociedad disciplinaria, establecido así a nivel mundial, por el teórico francés Michel Foucault. Sin embargo, esta sociedad disciplinaria, más allá de un mero control político sobre el ciudadano, lo que desea es: ayudar al crecimiento sostenido de lo que es una nueva teoría y práctica gubernamental, en donde, mediante la acumulación monetaria, el crecimiento de la población y el mercantilismo se conforma un "nuevo arte de gobernar" (Foucault, 2008-2010).

El liberalismo es, justamente, la racionalidad política que subyace a las nuevas formas del control que se despliegan en el territorio chileno, pues la forma de gobernar se basa en el control disciplinario, el cual, poco a poco se va extendiendo en el cuerpo social con la finalidad última de llegar al control de la vida biológica de las poblaciones.

Esta nueva tecnología del poder que se sustenta en el control biológico del individuo, se emprende solo en un contexto político liberal (Foucault, 2008), ya que es en el liberalismo donde se generan ciertas prácticas gubernamentales contradictorias, que por una parte hablan de la autonomía propia del ser humano -derechos individuales, libre mercados-y, a la vez, desarrolla una limitación sustentada en el control de lo que es la vida biológica del individuo en sí misma.

La biopolítica se presenta como una nueva estrategia política del poder, como una tecnología que se desarrolla en función de una visión biológica del ser humano, la que permite entender al sujeto social como una especie biológica asociada a relaciones y estrategias de poder que conforman un procedimiento que asegura la mantención de este mismo en el cuerpo social.

\section{Develamiento del liberalismo en Chile siglo XIX}

Luego de la batalla de Maipú, en 1818, Chile comienza a entrever su destino político (Salazar, 1999). Pues a medida que las juntas comienzan a dar frutos en el proceso de independencia respecto de la corona española, la reflexión política se despliega con ellas. Este hecho da origen a la construcción de Chile como una nación independiente que se traduce a un nuevo orden jurídico y a una nueva legitimidad en la afirmación de su soberanía política, económica y social.

La necesidad de contar con un nuevo orden gubernativo va a generar diversos desafíos constitucionales, que marcarán la pauta política de la construcción de un Estado. 
Los ensayos constitucionales fueron el intento de la clase dirigente y gobernante de Chile por formar un Estado que se ajuste a los modelos políticos entregados por Europa. La fusión de la reflexión política, de los ensayos constitucionales, ayudará a emerger la Constitución de 1833, en la que se plantea que nos debemos constituir como república sobre la base de la división de los poderes de Estado; teniendo como soberano al pueblo.

Sin embargo, la llegada de la Constitución de 1833 tuvo que pasar por un continuo cambio político, pues se quería realizar un Estado chileno bajo ciertos valores arraigados por la clase dominante de ese entonces, pero esto no era aceptado por todos los "ciudadanos activos" 3 .

El devenir histórico que va a presentar la reflexión política de este nuevo Estado influirá en la primera Constitución liberal de 1828; generando expresamente igualdad entre el poder ejecutivo y legislativo, fortaleciendo, con esto, los derechos políticos de la aristocracia emergente. Junto a esta nueva constitución donde el ideal republicano toma fuerte relevancia, el país comienza a poner en práctica su marco político institucional bajo la inspiración de un pensamiento liberal que promueve -con ciertas restricciones de la época- las libertades públicas, los derechos civiles, la independencia de los poderes y las garantías individuales. Lo que provocará una fuerte reacción del lado de los conservadores acarreando con esto una contienda donde liberales - pipiolos-y conservadores - pelucones- se enfrentan en una guerra civil en la que consiguen la victoria los conservadores (Salazar, 1999: 34).

Los conservadores, entonces, se posesionan del poder del Estado y junto a esto del control disciplinario, el que debe ser capaz de proclamar la disciplina como un programa de sociedad que busca ser aplicado a una multitud de individuos que son reacios a ser dominados.

Cuando Joaquín Prieto Vial asume su cargo el 18 de septiembre de 1831 se da inicio al periodo denominado "oligarquía" (Salazar, 1999). Tiempo después fue promulgada la Constitución Política de 1833, la que pretendía constituir una República basada en la división de los poderes del Estado, teniendo como soberano al pueblo. Sin embargo, se estableció un régimen de autoridad y de fuerza, recayendo todo el poder en manos de Prieto 4 .

El gobierno de Prieto se centrará específicamente en hacer efectiva una estricta economía donde crea una reforma tributaria y aduanera (Salazar, 1999), la que pone orden a las finanzas del país, comenzando con esto el auge de la minería impulsada,

Según la Constitución de 1823 no todos los individuos que viven en un territorio son ciudadanos. El ciudadano activo debía tener ciertas características políticas y económicas que los sustentaran como tal.

$4 \quad$ Las elecciones del Congreso y de los municipios iban a estar dirigidas por él, los intendentes y gobernadores; los jueces eran nombrados por él, al igual que los demás empleados de los servicios públicos. Era el generalísimo de las fuerzas armadas, dependiendo de él tanto el ejército como la marina y los cuerpos policiales. 
en ese entonces, por el ministro de Hacienda Manuel Rengifo, quien poco tiempo después renunciaría cediendo su puesto a Joaquín Tocornal, exministro de educación.

Es en 1835 cuando J.J. Prieto encomendó a Diego Portales como ministro interino de Guerra y Marina (Lastarria, 1861), cuando se comienza a desatar la paradoja del pensamiento liberal; por un lado, Portales reconoce las ventajas de los valores democráticos, pero insiste en que era previo el paso de un ajuste institucional caracterizado por un gobierno fuerte, centralizador y ajeno a las influencias partidarias, afirmando con este pensamiento la función de Prieto como Presidente de la República.

Es este episodio el que se devela como el momento histórico inaugural de la disciplina, como técnica gubernamental de control ciudadano. Este control ciudadano encuentra fundamento en la razón de Estado que pasa a ser defendida por el cuerpo policial (Maldonado Solar, 2007).

La expansión territorial que comienza a enfrentar el nuevo Estado chileno no está exenta de violencia, pues por el sur se encuentra con pueblos originarios que se resistían a la conquista y por el norte se enfrenta a Perú y Bolivia que tenían territorios con materias primas imprescindibles para el desarrollo económico de un Estado naciente (Salazar, 1999), lo que provoca que Perú y Bolivia se unifiquen en una confederación que se enfrentará en un conflicto bélico con Chile.

La guerra fue declarada el 28 de diciembre de 1836, un año después, Portales se hallaba pasando revista a las tropas en Quillota, cuando fue reducido a prisión (Lastarria, 1861), y al ser conducido a Valparaíso se le fusiló sin proceso. Corrían los primeros días de junio de 1837 y a los 44 años de edad el estadista era asesinado.

El asesinato de Portales lejos de borrar su forma de gobernar, asienta las bases del liberalismo en Chile dando paso a un nuevo control disciplinario y a un nuevo "arte de gobernar" donde ciertas técnicas, como es el control ciudadano y económico, ayudarán a un despliegue político óptimo dentro de lo que es esta nueva ciudadanía chilena.

\section{El surgimiento de la biopolítica en el Estado chileno}

Este punto de inflexión en la historia de la sociedad chilena va a marcar una nueva tecnología del poder estatal. La biopolítica puede emerger solo porque anterior a esta se despliega una forma de aplicar el poder, el que se traduce en la forma jurídica del poder, donde se vive la dualidad: "obediencia-transgresión"y que tiene como principal institución a la policía; la que ampara y hace obedecer la ley por medio del temor a la represión (Foucault, 2008). Sin embargo, la biopolítica ya no solo se centra en el sujeto social para controlar al individuo y hacerlo obedecer, sino que se presenta como dispositivo que controla cada una de las partes de la vida de ese sujeto social y, por tanto, a la población misma, redistribuyendo el poder como una mercancía de distribución donde la relación de fuerzas es constantemente puesta en tensión. 
Por todo esto, es necesario aclarar aún más el concepto de biopolítica, para así ir asimilando en mayor medida el análisis político-filosófico de la historia de Chile.

\section{Conceptos primordiales}

\section{Biopolítica:}

El concepto de biopolítica emerge principalmente por el filósofo francés Michel Foucault, quien marca las líneas actuales del debate biopolítico, él ha sido el primero en poner de relieve toda la amplitud de significados del término dando una importancia a los efectos sociopolíticos que esta nueva tecnología del poder va a provocar en el cuerpo social.

La biopolítica es una nueva estrategia del poder que pretende un control íntegro sobre la vida de los individuos que conforman una sociedad moderna. Para Michel Foucault el concepto de biopolítica corresponde a "la manera como se ha procurado, desde el siglo XVIII, la práctica gubernamental por los fenómenos propios de un conjunto de seres vivos constituidos como población: la salud, la higiene, la natalidad, la longevidad, la raza" (Foucault, 2010: 359). Lo que se define como biopolítica está directamente relacionado, entonces, con el Estado como representante del poder político que interviene en la manera que se constituye la vida de un ser humano.

Según Foucault, la biopolítica "emerge"en un tiempo determinado de la historia de la humanidad y en relación con dos procesos: la gubernamentalidad y el liberalismo como forma de gobernar en un Estado, ambos procesos sumamente ligados en el despliegue de la historia mundial y como se vislumbra, también, en la historia de Chile.

\section{La práctica gubernamental:}

Se entenderá como práctica gubernamental lo se denomina como "el arte de gobernar", es decir, la reflexión política de cuál es la mejor forma o manera de gobernar.

En la presente investigación se aplica esta definición para poder analizar de qué modo se establece un "dominio de la práctica de gobierno, sus reglas generales, sus diferentes objetos, sus objetivos de conjunto, para conseguir gobernar de la mejor manera posible" (Foucault, 2010,17) y, junto a esto, ver emerger la biopolítica en la nueva forma de gobernar en Chile.

\section{El Estado:}

Para Foucault el concepto de Estado es una dialéctica continua. "El Estado es a la vez lo que existe y lo que aún no existe en grado suficiente" (Foucault, 2010: 19), se entenderá que su existencia está dada en plural, pues existe por y para sí mismo, lo que implica que un Estado jamás deberá unificarse a un imperio, pues si esto sucede, deja de ser un Estado. Siempre que hablemos de Estado hablaremos de una razón 
de Estado, pues esta presenta una racionalización de una práctica, la que fija reglas y racionaliza teniendo como objetivo transformar en ser, el deber ser, del Estado" (Foucault, 2010: 19).

La ratio gubernamental permitirá que el deber hacer del gobierno se identifique con el deber ser de un Estado. Y si lo gubernamental es el arte de gobernar, entonces gobernar un Estado es actuar de tal modo que el Estado se despliegue en una continua permanencia, en una sólida estructura; aumentando riqueza y fortaleciendo el cuerpo de defensa contra los potenciales enemigos.

La pluralidad del Estado y su individualidad implicada en su pluralidad se plasma en formas de gobernar y en instituciones que ayudan a este propósito. Según Foucault, la primera manera de gobernar será por el lado económico; el mercantilismo, el que presenta una organización determinada de la producción y "circuitos" comerciales (Foucault, 2010: 155-180) que tienen la finalidad de enriquecer a un Estado mediante la acumulación de dinero, fortaleciendo el crecimiento de la población, y desarrollar, así, una suerte de competencia con las potencias extranjeras.

\section{El liberalismo:}

“...'Dejadnos hacer', porque allí está, a su juicio, el principio esencial que todo gobierno debe respetar y seguir en materia económica. En ese momento plantea con claridad el principio de la autolimitación de la razón gubernamental" (Foucault, 2010: 38-39), dice Foucault a partir de la reflexión del marqués de Argenson.

El "Dejadnos hacer" (Foucault, 2010: 38), principio esencial de todo gobierno liberal que deja la libertad supeditada a la libertad de mercado. Este mercado dirigido por este principio será la apertura del enriquecimiento, el crecimiento y el poder de un Estado, por tanto, este principio se incorpora como razón de Estado.

El liberalismo para Foucault se puede entender como una organización de métodos de transacción aptos para definir la limitación de las prácticas de gobierno, limitación al máximo de las formas y los ámbitos de acción del gobierno.

“...el análisis de la biopolítica solo puede hacerse cuando se ha comprendido el régimen general de esa razón gubernamental de la que les hablo, ese régimen general que podemos llamar cuestión de la verdad, primeramente de la verdad económica dentro de la razón gubernamental; y por ende, si se comprende con claridad de qué se trata en ese régimen que es el liberalismo, opuesto a la razón de Estado -o que antes bien la modifica de manera fundamental sin cuestionar quizás sus fundamentos-, una vez que se sepa qué es ese régimen gubernamental denominado liberalismo, se podrá, me parece, captar qué es biopolítica" (Foucault, 2010: 41).

Por tanto, se comenzará con un análisis histórico, para, así, poder llegar a dilucidar cómo se despliega las políticas económicas desde el surgimiento del liberalismo en Chile. 
El mercado será para el Estado liberal el centro de veridicción y un dispositivo de saber, pues su práctica se basa en intervenir a la población en el aseguramiento de las verdades de mercado donde los dispositivos de control y la formación de un cuerpo social serán los principios básicos de la utilidad de ese nuevo "arte de gobernar".

\section{Desenlace económico; hacia un Chile liberal}

El ideal de Portales:

"La República es el sistema que hay que adoptar; ¿pero sabe cómo yo la entiendo para estos países? Un Gobierno fuerte, centralizador, cuyos hombres sean verdaderos modelos de virtud y patriotismo, y así enderezar a los ciudadanos por el camino del orden y de las virtudes. Cuando se hayan moralizado, venga el Gobierno completamente liberal, libre y lleno de ideales, donde tengan parte todos los ciudadanos. Esto es lo que yo pienso y todo hombre de mediano criterio pensará igual.

¿Qué hay sobre las mercaderías de que me habló en su última? Yo creo que conviene comprarlas, porque se hacen aquí constantes pedidos. Incluyo en ésta una carta para mi padre, que mandará en el primer buque que vaya a Valparaíso.

Soy de Vd. Su obediente servidor

\section{Diego Portales" 5}

Este fragmento de la carta de Diego Portales sintetiza sus intereses como político, pues expresa su ideal de cómo se debe implementar un sistema político, también se logran ver reflejadas las actitudes empresariales y comerciales que este presentaba.

Portales crea las condiciones para que se genere un orden interno, plasmado en la Constitución de 1833, pues esta fue la proyección de un ideal de sociedad, que por sus características se acomoda a lo cultural del país y, por tanto, a una estructura económica que se trataba de consolidar gracias a personas con valores compartidos por el ministro.

La Constitución de 1833 nace como una reforma a la constitución establecida en 1828 (Lastarria, 1861), sin embargo, esta se solidifica y pasa a ser más que una mera reforma constitucional, puesto que busca solidificar un tipo de gobierno instaurado desde la época colonial.

5 Carta de Diego Portales a José M. Cea (marzo de 1822), Archivo histórico sacado de la pág. web: http: // historiachilexixudla.wordpress.com 
La Constitución de 1833 rigió durante 91 años, tiempo no menor para lo que significa el desarrollo político de un Estado, a los ojos de los políticos de ese entonces, esta Constitución viene a establecer un orden en el cuerpo socioeconómico de Chile:

"Despreciando teorías tan alucinadoras como impracticables (los constituyentes), solo han fijado su atención, en los medios de asegurar para siempre el orden y la tranquilidad pública contra los riesgo de los vaivenes de partidos que han estado expuestos. La reforma no es más que el modo de poner fin a las revoluciones y disturbios a que daban origen el desarreglo del sistema político en que nos colocó el triunfo de la independencia nacional. Es el medio de hacer efectiva la libertad nacional, que jamás podríamos obtener en su estado verdadero, mientras no estuviesen deslindadas con exactitud las facultades del gobierno y se hubiesen puesto diques a la licencia" (Valencia,1986: 172)

Cuando J.J. Prieto se refiere a las delimitaciones de los poderes observa ante todo la característica que tiene el presidente dentro de la Constitución, pues el presidente, según el artículo 81 de la Constitución analizada, se muestra casi con un poder monárquico aunque, en este caso, temporal pero absoluto; "su autoridad se extiende a todo cuanto tiene por objeto la conservación del orden público en el interior y la seguridad exterior de la República, guardando y haciendo guardar la constitución y las leyes" (C. P. Ch, 1833).

La figura del presidente tomará con esta Constitución un poder casi omnipresente, el que resguardará el orden interior y exterior ante todo, es decir, un "guardián" del orden cívico de Chile.

Las facultades del presidente con esta Constitución alcanza todas las ramas de la acción del Estado; no tan solo la de ser un guardián de la patria, sino que también la de estar presente en lo que respecta a la justicia, a la guerra, hacienda, relaciones exteriores y relaciones con el clero (C.P.Ch, 1833).

Por tanto, es particularmente responsable de las políticas que se establecen en materia de salud, educación, vivienda, trabajo, economía, etc. Es por ello que durante los siguientes años en Chile, heredero de liberalismo, se comienza a aplicar diversas estrategias para poder sustentar un proceso económico que debía conservarse en la libertad de mercado.

El discurso que se implementa con el liberalismo en los aspectos económicos entre 1830 y 1879 (Salazar, 1999) Ilevó al desarrollo a la industria manufacturera: molinos, refinación del azúcar, fabricación de vidrio, fundiciones metalúrgicas y otras industrias locales (Rippy, 1944: 21-54). Entre 1849 y 1852 se construyó el primer ferrocarril en Chile, que unía Caldera y Copiapó, generando un nivel de comunicación interna del país. En 1863 Santiago se unió por medio de una línea férrea con el principal puerto del país: Valparaíso.

Es en este periodo que aparece en la escena socioeconómica del país William Wheelwright, un ciudadano norteamericano, que construyó la línea telegráfica de 
Valparaíso a Santiago en 1851-1852; así se iniciaba un proceso que a fines de 1876 se extendió a cuarenta y ocho ciudades de Chile, y puso al país en comunicación rápida con Argentina y Perú mediante una línea a través de los Andes y un cable submarino bajo el océano Pacífico. Antes, en 1840, Wheelwright había traído a Chile los beneficios de la navegación de vapor, cuando fundó la Pacific Steam Navigation Company para establecer una línea de vapores de servicio regular entre Europa y las repúblicas sudamericanas de la costa del Pacífico.

Los beneficios económicos del país comenzaron a dar sus frutos a los mercaderes extranjeros (Ramón, 2003) y, como era de suponer, a la clase más acomodada del país. En 1905 la oligarquía chilena se asocia con las compañías foráneas por medio de una "ocupación económica del Estado", lo que provoca un alza en la acumulación de bienes privados y reduce el rol de la administración pública.

El éxito económico de Chile solo se reduce a un sector de la población, mientras mineros, pescadores, agricultores, artesanos se ven en desmedro respecto de los privilegios que obtenían los mercaderes de la época.

A pesar del malestar social de la época, ante la desigualdad económica6, las políticas estatales continuaron con un sistema económico donde se articula la gubernamentalidad con el liberalismo; obteniendo un Estado que no se mezcla con la economía para que así el mercado no entre en los límites de la justicia, aboliendo, con esto, cualquier resquicio de distribución equitativa de los bienes. Así, el precio justo cambia al precio natural-normal; el cual expresa una relación "adecuada" entre el costo de producción y la amplitud de la demanda (Foucault, 2010: 48).

"No se trata, desde luego, de que en sentido estricto los precios sean verdaderos, de que hayan precios verdaderos y precios falsos; no es eso. Pero lo que se descubre en ese momento, tanto en la práctica gubernamental como en la reflexión dedicada a ella; es que los precios, en cuanto se ajustan a los mecanismos naturales del mercado, van a constituir un patrón de verdad que permitirá discernir en las prácticas gubernamentales las que son correctas y las que son erróneas. [... E] El mercado, en la medida en que a través del intercambio permite vincular la producción, la necesidad, la oferta, la demanda, el valor, el precio, etc., constituye un lugar de veridicción, y con ello quiero decir un lugar de verificación y falseamiento de la práctica gubernamental" (Foucault, 2010: 49).

El Estado, por tanto, no puede intervenir en un sitio de veridicción o de verdad de la economía, sino que debe reducirse a las verdades que entrega el mercado y actuar en conjunto con ellas. El liberalismo debe tener ciertos rasgos que permitan identificarlo como tal; veridicción de mercado que genera junto a ella la utilidad gubernamental y así, un desarrollo ilimitado del mercado (Foucault, 2010: 62-90).

6 Desigualdad social aún presente en nuestra sociedad. 
Es específicamente esta situación la que provoca el surgimiento de la biopolítica en el Estado chileno, pues el liberalismo gestado por Portales y heredado por la clase de la política de nuestro país analizará de tal forma al Estado que dentro de ese dispositivo (Deleuze, 1988: 155-153) de limitación gestará el conocimiento del escenario donde se despliega, es decir, el liberalismo determinará los mecanismos de acción de un Estado encontrando y desarrollando la biopolítica como mecanismo de control de la población en todo ámbito de su vida.

El mercado que se convierte en razón de un Estado, porque es una verdad de Estado y como el Estado no puede incidir en el sitio de veridicción de la economía actúa sobre quienes crean y provocan el desarrollo de esta: la población, y es acá donde la nueva tecnología política del poder abarca a todos los ámbitos de la vida humana.

Cuando en Chile aparece el capital extranjero se comienza a desarrollar una veridicción de mercado y la modernización propia del Estado en sus estrategias de poder se mezcla con el control policial y el control biopolítico en el cuerpo del sujeto social.

Al nacer la biopolítica en Chile como una tecnología que sustenta un poder dentro del cuerpo social y del individuo. Se desarrolla una mezcla de control ciudadano, pues por una parte se tiene al cuerpo policial que controla, a través del miedo, la construcción de una obediencia civil y por otra tenemos al control completo de la constitución de la especie humana -la biopolítica-.

El hecho que se genere esta nueva tecnología política del poder en nuestro Estado, hace que el control político sobre la ciudadanía se dé de tal manera que disciplinariamente parezca natural en el cuerpo del individuo (Foucault, 2008). La incidencia de la biopolítica en el control biológico del individuo no apunta solamente a un aseguramiento del poder del Estado, sino que también y, por sobre todo, desea el mantenimiento de un capital que se genera en la población misma. Es por ello que la población debe expandirse lo más posible para así sustentar y entregar al Estado lo que del ciudadano se desea: ganancia económica, pues mientras, más ciudadanos existan bajo el control del Estado más capital obtiene ese Estado.

El desarrollo de las técnicas políticas que sustentan el poder de un Estado se genera de tal forma que uno de los puntos de mira que enfrenta esta forma de control será el cuerpo que por naturaleza puede engendrar, y por tanto, generar más población; es decir, el cuerpo de la mujer.

\section{II}

\section{La biopolítica en el cuerpo de la mujer}

"El liberalismo plantea simplemente lo siguiente: voy a producir para ti lo que se requiere para que seas libre. Voy a procurar que tengas la libertad de ser libre. Y al mismo tiempo, si ese liberalismo no es tanto el imperativo de la libertad como la 
administración y la organización de las condiciones en que se puede ser libre, verán con claridad que en el corazón mismo de esa práctica liberal se instaura una relación problemática, siempre diferente, siempre móvil entre la producción de la libertad y aquello que, al producirla, amenaza con limitarla y destruirla. El liberalismo, tal como yo lo entiendo, ese liberalismo que puede caracterizarse como el nuevo arte de gobernar conformado en el siglo XVIII, implica en su esencia una relación de producción/ destrucción [con] ${ }^{*}$ la libertad []. ${ }^{*}$ Es preciso por un lado producir la libertad, pero ese mismo gesto implica que, por otro se establezcan limitaciones, controles, coerciones, obligaciones apoyadas en amenazas, etc." (Foucault, 2010: 84).

Cuando hablamos de biopolítica como tecnología política del control de la vida biológica de las poblaciones, es imposible no reflexionar en torno a la mujer, quien representa, genéricamente, un sujeto-objeto de nuestra sociedad. A ella, se le han presentado "limitaciones" dentro de su libertad desde el origen del concepto de familia (Beauvoir, 2008).

La alianza de una nueva tecnología del poder junto a una nueva visión de lo que es el "arte de gobernar" (Foucault, 2008/2010) creará nuevos elementos necesarios para entender cómo, entre qué, entre quiénes y de acuerdo con qué procedimiento existe un mantenimiento del poder creado entre un individuo contratante y la sociedad como producto del contrato.

El elemento que se analizará en esta parte del presente artículo tiene que ver con el surgimiento de la noción de "población". Esta representa un nuevo cuerpo que implica un problema biológico y de poder, pues la génesis de esa población es la mujer dominada por una forma económica, política y genérica que obedece a las doctrinas patriarcales de una sociedad como lo es Chile (Kirkwood,1990).

La mujer que es la principal responsable de su "destino fisiológico" se ve como al organismo que cumple con la perpetuación de la especie; función principal para la expansión de los brazos productores de un Estado.

La regulación de esta capacidad fisiológica de la mujer es un elemento que se encuentra en la razón de un Estado liberal, pues la expansión de la población, como objeto productor genera: el mercado; instancia construida y protegida en el liberalismo y neoliberalismo en la medida en que el gobierno legisla a favor de ciertas protecciones del mercado que tienen la finalidad de organizar a la población en vista de un proceso económico (Foucault, 2010). Proceso que crea una desigualdad de derechos entre los ciudadanos de una población, pues lo que invade la técnica biopolítica es a la mujer y su cuerpo. Esta invasión es patente cuando se entromete en la legislación relativa a los derechos reproductivos, cuando esta legislación debería ser un asunto en que la misma mujer ejerce soberanía en cuanto ciudadana afectada.

Los mecanismos del poder, que circulan desde la disciplina al biopoder, se aplican tanto al cuerpo como a la población. Esto permite "controlar el orden disciplinario del cuerpo" (Foucault, 2008) - de la mujer-generando una dirección intencional al cuerpo 
de la población. Es decir, la biopolítica controla y regula a la población con métodos que obedecen a una lógica económica que al disminuir la regulación de las normas jurídicas, resguarda, a su vez, por medio del control disciplinario, los intereses de la razón económica del Estado.

La regulación de las normativas jurídicas en lo que respecta al derecho de reproducción de la mujer, son ejes principales del interés biopolítico. La natalidad y la fecundidad de una población generan resguardos y prohibiciones bajo una justificación valórica, que obedece netamente a la mantención de una producción de cuerpos, de sujetos, de individuos sociales; como objetos que generan un aporte al desarrollo económico de un Estado.

La correlación entre gobernante (s) y gobernada (s) se genera como una relación de poder, donde la mujer es el punto de resistencia, y el gobernante es el defensor de un mercado que resguarda a la vida humana con la finalidad de tener entes productivos dentro de su libre economía.

Las políticas sobre la regulación de la fertilidad en Chile se generan disyuntivamente a lo largo de la historia neoliberal. Aquí se analizará especialmente el siglo XX, pues es en este periodo cuando se producen más "regulaciones" respecto del derecho reproductivo de la mujer, en lo relativo al aborto.

\section{Políticas reproductivas en Chile: siglo XX}

La paradoja liberal de entregar libertades, pero controlar el cuerpo y el útero de la mujer es un mecanismo regulador que incide directamente sobre el control de una población.

A comienzos del siglo XX, la mujer comienza a organizarse en agrupaciones para frenar la exclusión de la educación, del trabajo, de la política, y de sus derechos reproductivos. La libertad de la mujer se ve limitada por las restricciones de un sistema patriarcal, donde la base de producción se relaciona con una economía que no le interesan los afectados, ignorando así los problemas de una parte de la población que exige llegar a ser reconocida en derechos como una ciudadana, en cuanto al poder decidir y legislar en políticas que atañen netamente al cuerpo de la mujer.

La supuesta tradición de la República de Chile indica que es el Estado quien tiene la responsabilidad de velar por la salud de toda una ciudadanía. Una de las políticas de salud más acabadas es la legislación respecto de la fertilidad de las mujeres, que dentro de la lógica neoliberal funcionan bajo un lugar social inferior que el que ocupa el hombre, pues toda su función está bajo los condicionamientos propios de la maternidad (Beauvoir, 2008) sin tener en cuenta otros aspectos y opciones de vida que permiten el desarrollo óptimo de la ciudadanía en una comunidad. 
Entender las relaciones reproductivas al margen de las relaciones de poder entre el hombre y la mujer, es no comprender que existe una arraigada y atávica jerarquización, que se muestra en la base genérica de los seres humanos y que es representada en el rol que se le da a una mujer en un Estado desde el comienzo de una cultura patriarcal, estandarizada por la historia de occidente.

La relación de poder que se solidifica en un hábitat patriarcal es consecuencia del nacimiento, a finales del siglo XIX, de diversos movimientos femeninos a nivel mundial, los que han realizado la resistencia desde lo más difícil; ser mujer y tener una condición de asalariada.

En Chile, los movimientos por la defensa de los derechos como la regulación de la fecundidad se inician con la creación del Movimiento Pro Emancipación de la Mujer Chilena (MEMCH) (Kirkwood, 1990). Hacia mediados del siglo XX, las mujeres de estratos populares al no tener métodos para limitar su fecundidad recurrían a prácticas casi "mágicas" como métodos anticonceptivos y por tanto al aborto, lo que junto con una crisis económica y de salud deja efectos deplorables en la calidad de vida de la mujer y de la población en vista a un desarrollo.

El MEMCH fue una de las organizaciones reflexivas analíticas y prácticas que entendieron que la mujer chilena es un ser arraigado en una cultura patriarcal (Kirkwood, 1990), inmersa en mecanismos hegemónicos del poder y que por tanto esta mujer chilena no se construye como una verdadera ciudadana por el hecho de trabajar y vivir en una ciudad, sino que se es ciudadana cuando se está sujeta a una igualdad de derechos dentro de un Estado. Sin embargo, el tema de la mujer chilena y ciudadana no era ni es una cuestión que importe al gobierno, es decir, las peticiones o el fenómeno propiamente tal sobre la constitución ciudadana no es una razón gubernamental en Chile?.

"Ya en esos años se proponía el mejoramiento de los salarios femeninos, proteger a la madre soltera, admitir en los casos pertinentes el divorcio con disolución de vínculo, promover una educación sexual científica y sin falsa moral, y terminar con el complejo de inferioridad que la sociedad había inculcado a las mujeres, todo lo cual haría posible acabar con la prostitución, otro de los grandes males de la época" (Dides. C, 2006).

La salud reproductiva y sexual no alude únicamente a un bienestar respecto de reproducción, sino que es una construcción "integral", donde se da por entendido el derecho de las personas a reproducirse y a regular su fecundidad dentro de la sociedad, y por consiguiente, a que el cuerpo femenino no se vea afectado frente a embarazos o parto riesgosos, lo que apunta a tener una vida sexual sin sacrificios.

El hecho que las mujeres estén dentro de la producción económica y, por tanto, ocupar puestos genealógicamente de hombres, hace creer a la población que existe la mujer ciudadana, sin embargo, esto es una falsedad que hace confundir al imaginario colectivo, pues mientras la mujer no pueda decidir por su cuerpo y su reproducción NO PUEDE LLEGAR A SER UNA CIUDADANA. 
Las decisiones sobre la reproducción, sexualidad y maternidad comprometen la autonomía propia de un ser humano, en este caso, la autonomía de la mujer, pues es la mujer quien debe decidir como sujeto político su propio plan de vida en sociedad. Sin embargo, esa autonomía es limitada ipso facto, por ejemplo, cuando una mujer decide poner fin a su vida reproductiva por medio de la esterilización, ejerciendo su "autonomía sexual", encuentra una fuerte oposición que se sustenta en las convicciones de los profesionales de la salud. Estos suelen actuar por razones médicas y no por razones de liberación autónoma del sujeto en sociedad ${ }^{8}$.

Por todo esto, Chile y las instituciones políticas con fundamentos religiosos y morales validan a la familia entendiéndola como una institución donde la protección de la vida debe ser lo principal. Dentro de ese núcleo familiar moralizado la sexualidad es un tabú y, por tanto, las consecuencias de esa sexualidad no hablada limitan las herramientas de anticoncepción necesarias, y conlleva a una situación inevitable: el embarazo, lo que limitará a la mujer, pues la visión que se instaura dentro de lo social sobre la mujer se reducirá a ser $\mathrm{LA} \mathrm{MADRE}^{9}$, abandonando, dentro de un mismo cuerpo, a la MUJER "ciudadana".

La maternidad en la sociedad chilena y en el mundo es una imposición violenta contra las mujeres, pues nacer con una condición dada por la "naturaleza"10 es lo más violento que un "ciudadano libre" (Beauvoir, 2008) puede llegar a experimentar. La condición de porque eres mujer debes ser madre reduce las potencialidades de la mujer en sí misma.

Desde la antigüedad se reduce a la mujer a su maternidad. El que una mujer por condición biológica tenga útero no la sujeta a que esta deba ser madre ${ }^{11}$, mas la costumbre patriarcal ha afirmado durante siglos que esa mera condición femenina es una deficiencia de esta y por tanto debe acatar lo que se le designa en nombre de lo "natural".

Aristóteles definía a la mujer como una hembra que es deficiente e incapaz de preparar su fluido menstrual al punto del refinamiento, en el cual se convierte en semen (es decir, semilla). Por lo tanto, su única contribución al embrión es su materia, dirá Aristóteles, un campo en el cual pueda crecer. Su incapacidad para producir semen es su deficiencia (Aristóteles, 1988).

$8 \quad$ Resolución Exenta № 2326 de 2000, publicado en el Diario Oficial del 9 de diciembre de 2000: "20.- Se podrá acceder a la esterilización a petición de la persona solicitante, por recomendación médica o a solicitud de terceros, en casos especiales".

9 Visión naturalista-reductiva de lo que es la mujer en todo su ser.

10 Solo por el hecho de ser mujer esta debe reproducirse, casarse, criar hijos, hacer las labores de hogar.

11 Aunque para algunas mujeres el hecho de ser madres puede llegar a significar psicológicamente algo muy beneficioso - por los mismos cánones sociales entregados-, pero como también puede ser algo adverso e incluso funesto. 
La visión reduccionista de la mujer-matriz-útero desde el origen del pensamiento occidental marca el destino de lo que será el desarrollo de la mujer respecto de su maternidad.

La maternidad pasa a ser dentro de la nueva tecnología política del poder un elemento central de administración de la vida, pues es la maternidad el blanco de dominación del cuerpo de la mujer. La maternidad entonces pasa a ser, como lo dice Rich, una gran malla en la cual todas las relaciones humanas están entrelazadas, donde se esconden nuestras suposiciones más elementales sobre el amor y el poder (Rich, 1983).

La estrategia de la biopolítica en el cuerpo de la mujer es entonces la medicina y las normativas representadas en las legislaciones jurídicas, las que controlan, vigilan la natalidad y prohíbe el aborto.

\section{El aborto en Chile}

Las justificaciones religiosas, morales y valóricas que se insertan dentro de una sociedad "falocéntrica" requieren el resguardo de una disciplina médica que desde sus orígenes ampare un sistema hegemónico entregado por la seguridad de un imaginario colectivo patriarcal donde el hombre constituye básicamente la especie humana.

La concepción androcéntrica del mundo de la medicina en el sistema liberal invade a sus técnicas disciplinarias y con ello a todo el cuerpo social, apoderándose de los espacios político-biológicos, excluyendo así a la que históricamente ha sido la curandera $^{12}$. Con todo esto, el ejercicio médico impone una visualización del cuerpo femenino que despoja a la propia mujer de las decisiones sobre el uso de su cuerpo ${ }^{13}$.

El hecho de despojar a una mujer de la decisión fundamental sobre el uso de su propio cuerpo es una violencia simbólica, pues genera que los derechos de reproducción sean decididos por otros, especialmente por las instituciones de salud pública, las que se encuentran bajo el alero de una economía-moralizada que evita a la mujer ser una verdadera ciudadana.

El despojo violento que sufre la mujer sobre las decisiones de su propio cuerpo, en una comunidad como lo es Chile, demuestra y representa la visión que tiene el Estado en materias de libertad femenina, lo que delata una cultura retrógrada y arcaica con pensamientos morales que muchas veces no hacen más que justificar la criminalización de la mujer en lo que respecta a la decisión de no ser madres.

12 Dentro de la tradición de las comunidades originarias, el rol de la mujer constituía ser una sanadora el conocer el mundo de las hierbas naturales y la relación estrecha con el alimento, hacía que la comunidad confiara en la sanación entregada por la curandera, la sanadora, la bruja, la machi, etcétera.

13 El sistema androcéntrico ha patologizado la conducta sexual de la mujer, ejemplo claro es la histeria, la menopausia, la menstruación y todos los procesos biológicos que se enfrentan a una concepción de anormalidad. 
A lo largo de la historia, Chile contó con un artículo dentro de su código sanitario que permitía interrumpir el embarazo por razones terapéuticas durante los primeros meses de gestación evitando que la mujer sea criminalizada por el hecho de no tener un hijo.

El código sanitario de 1931 fue el único código de nuestro país que en materia de aborto ha tenido coincidencia entre el código penal y lo médico-legal.

En 1989, la dictadura militar aprobó la derogación del artículo 119 de la ley 18.826, prohibiendo el aborto y criminalizándolo con pena de presidio por el Código Penal.

\section{LEY NÚM. 18.826 \\ SUSTITUYE ARTÍCULO 119 DEL CÓDIGO SANITARIO}

La Junta de Gobierno de la República de Chile ha dado su aprobación al siguiente Proyecto de ley

Artículo único.- Reemplázase el artículo 119 del Código Sanitario por el siguiente:

"Artículo 119.- No podrá ejecutarse ninguna acción cuyo fin sea provocar un aborto".

JOSE T. MERINO CASTRO, Almirante, Comandante en Jefe de la Armada, Miembro de la Junta de Gobierno.

FERNANDO MATTHEI AUBEL, General del Aire, Comandante en Jefe de la Fuerza Aérea, Miembro de la Junta de Gobierno.

RODOLFO STANGE OELCKERS, General Director, General Director de Carabineros, Miembro de la Junta de Gobierno.

SANTIAGO SINCLAIR OYANEDER, Teniente General de Ejército, Miembro de la Junta de Gobierno.

Por cuanto he tenido a bien aprobar la precedente ley la sanciono y la firmo en señal de promulgación.

Llévese a efecto como Ley de la República.

Regístrese en la Contraloría General de la República, publíquese en el Diario Oficial e insértese en la Recopilación oficial de dicha Contraloría.

Santiago, 24 de Agosto de 1989.

AUGUSTO PINOCHET UGARTE, Capitán General, Presidente de la República.Hugo Rosende Subiabre, Ministro de Justicia.- Juan Giaconi Gandolfo, Ministro de Salud Pública.

Lo que transcribo a Ud. para su conocimiento.- Jorge Beytía Valenzuela, Capitán de Navío JT, Secretario de Legislación de la Junta de Gobierno. 
Este artículo del código sanitario que actualmente impera es la clara impronta de una violación a los derechos fundamentales de una mujer en comunidad. No necesitamos ser sigilosos para darnos cuenta que la derogación es realizada y proclamada por un grupo de hombres, quienes representan un poder dictatorial -pero eso es de accidente-, pues en Chile las normativas al derecho de elegir y decidir sobre la maternidad siempre ha pasado por la decisión de instituciones representadas por hombres que legislan el comportamiento valórico, legislativo y práctico de la mujer.

El hecho que los hombres legislen respecto de una "condición natural de la mujer" impuesta por la sociedad, claramente, habla de una concatenación de actos para que estos hombres sean los que legislen, y estén en ese lugar.

La relación de poder entre hombres legisladores y mujeres legisladas habla de una tradición que anula la conducta social-ciudadana-política de las mujeres de tal manera, que la justificación de maternidad obedece a tener una condición natural instintiva de ser madres, más el terrible rol designado a la mujer por el pensamiento cristiano como por ejemplo: "Yo no permito que la mujer enseñe ni que ejerza autoridad sobre el hombre, sino que permanezca callada" (1Tm. 2,12). O, "que las mujeres estén calladas en las asambleas, no les corresponde tomar la palabra. Que estén sometidas, como lo dice también la ley" (1Co. 14,34). Genera una idea de superioridad del hombre, con valores cristianos-normalizantes, ante la mujer. Por tanto, los métodos de control que son aplicados a la sociedad en su conjunto se agudizan aún más en la mujer y en su cuerpo, pues la mujer es la dominada y el punto de resistencia del poder disciplinario (Foucault, 2008).

Cuando se deroga un artículo tan importante como lo es el artículo 119, se debe asegurar que si se llega a agraviar la ley la ciudadana o el ciudadano será sancionado por esta. Por tanto, una vez que se deroga el artículo 119 se fortalecen las penas dentro del Código Penal ${ }^{14}$ y se tipifica los siguientes delitos del aborto:

Aborto realizado por tercero no profesional de la salud con consentimiento de la mujer.

(Artículo 342, n³): 541 días a 3 años.

Aborto causado por tercero profesional de la salud (Art. 345). La pena depende de si el aborto fue consentido o no, con o sin violencia, según lo señalado precedentemente.

Aborto causado por la propia mujer:

Auto aborto (artículo 344, inc. 10): 3 años y 1 día a 5 años.

Aborto honoris causa o con el fin de proteger su honra (artículo 344, inc. 20): 541 días a 3 años.

Cuasidelito de aborto cometido por un tercero (artículo 343): 61 días a 3 años.

14 Código Penal de la República de Chile, libro II. 
Todos estos actos tipificados por presidio tienen una única finalidad, que es proteger a las "futuras generaciones", pues se intenta que por medio del control disciplinario y de la biopolítica se proteja a la vida que está por nacer, pues la base del desarrollo de la economía liberal chilena en la dictadura de Augusto Pinochet consistía -y consiste- en componer un país desarrollado bajo el alero de productividad de la misma población y mientras más mano de obra, mejor para el mercado económico.

La política siniestra de la dictadura de Pinochet consistía en proteger a la fuerza productiva que viene dentro de un futuro próximo y por otra parte -en su maquiavelismo- destruir al sujeto social que no llegaba a ser controlado ni disciplinado ante los mandamientos de un sistema totalitarista. Por tanto, la familia en este instante pasa a ser de una preocupación pública, y la influencia clara de la biopolítica emerge al ser parte de la nueva técnica de control y de dominación en el cuerpo de la mujer.

La normativa establecida por la dictadura como por el gobierno de transición o democráticos, en lo que respecta a la legitimación de la no propiedad decisiva de la mujer, se manifiesta en toda la vida de la población, lo que facilita la inserción de discursos ${ }^{15}$ que se mezclan con los valores fundamentales del mercado, logrando imponer un imaginario criminalizante sobre el cuerpo de la mujer y el aborto.

La relación de poder que se dará entre lo gubernamental, lo legislativo y el cuerpo mismo de la mujer no es una mera relación de poder, pues se puede llegar a pensar que si se anulan las prohibiciones, en este caso, del aborto, se anula el poder que controla ese cuerpo y por tanto se libera el cuerpo femenino.

Para Foucault las tecnologías políticas del poder, las que controlan, vigilan y castigan al sujeto social, más allá del hecho de prohibir, intensifican la eficacia y aptitudes, logrando fomentar el aparato productivo de la sociedad.

Por tanto, si se prohíbe el aborto a una mujer incrementará la población, si aumenta la población aumenta las demandas productivas de un país, y es por ello, que LA FAMILIA cobra un sentido tan relevante en una sociedad chilena, pues se convierte en un instrumento privilegiado para el gobierno porque es la base de la población. Y ¿cuál es el objetivo o núcleo central de la biopolítica?; La población (Foucault, 2010).

Si la población es el objetivo fundamental de la biopolítica, entonces, si quiero conseguir algún control o cambio en una conducta específica en lo que respecta al incremento de la población, o al comportamiento sexual de la población, se debe controlar el elemento base, primordial y fundamental de la población: la mujer y su cuerpo.

15 Como cuidar la vida futura del nonato como derecho de protección de una vida creada por Dios: "Todas las personas que creen en Dios están de acuerdo en que Dios es Quien concede los hijos y Quien infunde el alma en el cuerpo humano. Ello significa que Dios crea a cada ser humano para un propósito. No tenemos el derecho de contradecir Su voluntad respecto de Su creación". Documento extraído de Iglesia.org sitio católico que nació en 1996, creado por sacerdotes, estudiantes, hombres y mujeres que profesan la religión católica. 
Es por ello que se intenta diagnosticar en qué momento este mecanismo tecnológico del poder, como una nueva forma de control, incide en la vida de la mujer chilena y cómo se genera una fusión entre patriarcado-liberalismo-biopolítica-mujer.

El diagnosticar, visualizar y develar el control biopolítico nos ayuda a comprender cuáles son los dispositivos biopolíticos que controlan el cuerpo de la mujer en el Estado chileno, para así, desde esa conciencia y resistencia se genere otra política que no lleve en su imaginario conductas como el no permitir decidir sobre los derechos reproductivos femeninos $y$, por tanto, no permite a la mujer vivir una verdadera ciudadanía, pues no se puede manifestar respecto de algo que le pertenece: su cuerpo.

Al ser un proceso de develación de un control político nos invita a una reflexión sobre " el porqué y el cómo de la opresión, y las formulaciones para su posible negación" (Kirkwood, 1990).

\section{BIBLIOGRAFÍA}

Aristóteles: De la generación de los animales en "Obras Completas", Editorial Gredos, Madrid, 1988/2005.

Constitución Política de la República de Chile 1833.

De Beauvoir, Simone: El Segundo Sexo, Ed, Debolsillo, 2008.

De Ramón, Armando: Historia de Chile. Ed. Catalonia, 2003.

Dides, C.: Voces de emergencia: el discurso conservadory la píldora del día después. Santiago de Chile: FLACSO-Chile, UNFPA; 2006.

Foucault, Michel: Nacimiento de la Biopolítica. Ed. Fondo de Cultura Económica, Buenos Aires, 2010.

Foucault, Michel: Vigilar y castigar, el nacimiento de la prisión. Siglo XXI, 2008.

Gilles Deleuze: En Michel Foucault Filósofo, ¿Qué es un dispositivo? Gedisa, 1988.

J. V. Lastarria: Don Diego Portales. Juicio histórico, Santiago. Imprenta de El Correo, 1861

Kirkwood, Julieta: Ser política en Chile; los nudos de la sabiduría feminista, editorial Cuarto Propio, 1990.

La Biblia, editorial Verbo Divino,1989.

Maldonado Solar, Elizabeth (2007): "La cárcel: un engranaje más del poder". Tesis (Licenciatura en Filosofía).Valparaíso de Chile: Universidad de Valparaíso, Facultad de Humanidades, Instituto de Filosofía. 
La biopolítica: una nueva técnica de control en Chile

Rich, Adrienne: Sobre mentiras, secretos y silencios. Ed. Icaria, 1983. Barcelona.

Rippy, F.: LatinAmerica and the Industrial Age (New York, 1944).

Salazar, Gabriel: Historia Contemporánea de Chile l: Estado, legitimidad, ciudadanía. Ed. Lom.1999.

Valencia Avaria, Luis: Anales de la República. Editorial Andrés Bello, 1986. 